\title{
Myocardial contractility and total arterial stiffness in patients with overt hyperthyroidism: acute effects of $\beta_{1}$-adrenergic blockade
}

\author{
E A Palmieri, S Fazio, V Palmieri ${ }^{1}$, G Lombardi $^{1}$ and B Biondi ${ }^{2}$ \\ Departments of Clinical Medicine and Cardiovascular Sciences, ${ }^{1}$ Clinical and Experimental Medicine, and ${ }^{2}$ Clinical and Molecular Endocrinology and \\ Oncology, University Federico II School of Medicine, Napoli, Italy
}

(Correspondence should be addressed to E A Palmieri, Department of Clinical Medicine and Cardiovascular Sciences, Via S Pansini, 5 Edificio 18 , 80131 Napoli, Italy; Email: eapalmieri@ciaoweb.it)

\begin{abstract}
Objectives: To ascertain whether myocardial contractility and total arterial stiffness are significantly altered in human thyrotoxicosis, and to what extent they are affected by acute $\beta_{1}$-adrenergic blockade.

Methods: Doppler-echocardiography was used to assess left ventricular (LV) structure and function, hemodynamics and total arterial stiffness in untreated overt hyperthyroid patients before and $2 \mathrm{~h}$ after $5 \mathrm{mg}$ bisoprolol given orally compared with age- and sex-matched healthy euthyroid controls. Results: Compared with controls, untreated patients $(n=20)$ had a higher heart rate (HR) and LV stroke index (SI), which were associated with higher pulse pressure (PP), larger LV end-diastolic volume index (EDVI, an index of preload, $+11 \%, P<0.05$ ), marginally increased stress-corrected LV midwall fractional shortening (MWS, an index of myocardial contractility, $+5 \%$; $P=0.066$ ), and shorter isovolumic relaxation time (IVRT). These changes resulted in a higher cardiac index (CI) and a lower systemic vascular resistance (SVR), which were associated with fairly normal mean blood pressure (BP) but higher PP/stroke volume (an index of total arterial stiffness, $+29 \%$; $P<0.01)$. After bisoprolol, compared with controls, the randomly treated patients $(n=10)$ had comparable HR but additionally increased SI; PP remained enhanced, EDVI was further enlarged $(+26 \%$, $P<0.001)$, stress-corrected MWS was substantially unchanged, and IVRT remained shorter. Overall, these effects attenuated the high-output state, which was associated with normalization of $\mathrm{PP} /$ stroke volume without changes of mean BP.

Conclusions: In human overt hyperthyroidism, myocardial contractility does not play a major role in increasing LV performance, which is instead predominantly sustained by increased preload with enhanced LV diastolic function. In addition, human thyrotoxicosis is associated with increased total arterial stiffness despite fairly normal mean BP. In this scenario, acute $\beta_{1}$-adrenergic blockade blunts the cardiovascular hyperkinesia predominantly by slowing HR - a process that is associated with normalization of total arterial stiffness.
\end{abstract}

European Journal of Endocrinology 150 757-762

\section{Introduction}

Overt hyperthyroidism exerts remarkable effects on the heart and vasculature leading to a well recognized hyperkinetic cardiocirculatory state (1). However, it is unclear whether, in humans, thyrotoxic cardiovascular hyperkinesia is predominantly sustained by changes in myocardial contractility, or by changes in peripheral hemodynamics (2). This uncertainty is at least partially fuelled by the fact that the increased $\beta_{1}$-adrenergic activity that characteristically accompanies overt hyperthyroidism may confound the analysis of the genuine effects of thyroid hormone on the heart and vasculature (2). In addition, it is not known whether total arterial stiffness is changed in human overt hyperthyroidism (2).
Accordingly, we evaluated left ventricular (LV) structure and function, hemodynamics and total arterial stiffness by Doppler-echocardiography in newly diagnosed and untreated overt hyperthyroid patients before and soon after $\beta_{1}$-adrenergic blockade, as compared with age- and sex-matched healthy euthyroid controls.

\section{Subjects and methods}

\section{Patients' characteristics and study protocol}

Twenty patients with overt hyperthyroidism (thyrotropin (TSH): $<0.03 \mathrm{mU} / \mathrm{l}$ (reference range, $0.3-3.8$ ); free-thyroxine $\left(\mathrm{F}-\mathrm{T}_{4}\right), \quad 44.4 \pm 9.5 \mathrm{pmol} / \mathrm{l}$ (reference range, $\quad 7.7-20.6) ; \quad$ free-triiodothyronine $\left(\mathrm{F}-\mathrm{T}_{3}\right)$, 
$21.4 \pm 6.5 \mathrm{pmol} / \mathrm{l}$ (reference range, 4.0-9.2)), and 20 healthy euthyroid controls matched by sex and age (TSH: $1.63 \pm 0.42 \mathrm{mU} / \mathrm{l}, \quad P<0.001 ; \quad \mathrm{F}_{-} \mathrm{T}_{4}$, $12.1 \pm 2.0 \mathrm{pmol} / \mathrm{l}, \quad P<0.001 ; \mathrm{F}_{-} \mathrm{T}_{3}, 6.9 \pm 0.9 \mathrm{pmol} / \mathrm{l}$, $P<0.001)$ entered the study after giving informed consent. Hyperthyroid patients, recruited from a pool of outpatients with newly diagnosed and untreated Graves' disease, were enrolled in the study if they had a sedentary life style, were not taking medication, and had no clinical or anamnestic evidence of non-thyroidal illnesses. The mean duration of hyperthyroidism was $6.6 \pm 1.6$ months (range: 4-9 months), as assessed from a detailed medical history. Healthy control subjects were recruited from a large group of outpatients evaluated for atypical chest pain and/or palpitations. All had a sedentary life style and none had clinical or biochemical evidence of thyroid or non-thyroidal disease.

Basally, all participants underwent noninvasive cardiovascular assessment (see below). In addition, a subgroup of 10 randomly selected hyperthyroid patients were re-evaluated $2 \mathrm{~h}$ after oral administration of $5 \mathrm{mg}$ bisoprolol (a $\beta_{1}$-adrenergic blocker), and compared with a subgroup of 10 age- and sex-matched controls. We used this dose of bisoprolol because of preliminary experience showing a heart rate reduction of about $20 \%$ in overt hyperthyroid patients compared with the pretreatment value $2 \mathrm{~h}$ after oral administration of the drug (S Fazio, personal observation).

\section{Echocardiographic methods}

Using a standard echocardiographic protocol according to the American Society of Echocardiography recommendations (3), we conducted a two-dimensionally guided M-mode analysis of LV morphology and LV filling with an ultrasound machine equipped with a 2.5-3.5 MHz transducer (Apogee CX, Interspec, Inc., Ambler, PA, USA). All subjects were examined while in a supine lateral position after resting for $30 \mathrm{~min}$. M-mode and Doppler echocardiographic tracings were acquired during quiet respiration and were recorded on a strip-chart recorder at a paper speed of $100 \mathrm{~mm} / \mathrm{s}$. ECG tracing was displayed simultaneously on the echo-tracings. Three cardiac cycles were averaged for measurements. Brachial artery pressure (blood pressure (BP)) was measured by cuff-sphygmomanometer after the echocardiographic study with subjects in supine decubitus.

\section{Echocardiographic measurements}

LV end-diastolic and end-systolic diameters (EDD and ESD), interventricular septal (EDIVS and ESIVS) and posterior wall thicknesses (EDPWT and ESPWT) were measured from M-mode tracings according to the Penn convention (4). LV end-diastolic and end-systolic volumes (EDV and ESV) were obtained by two-dimensional echocardiography with the single plane area-length method (5), and were indexed for body surface area (EDVI and ESVI). The intra-observer variability for LV structure and volume, calculated as the percentage difference between reading sessions (6), was $<8 \%$ and $<13 \%$ respectively. Early (E wave) and late (A wave) peak transmitral flow velocities of LV fillings were sampled at the tip of the mitral valve by pulsedwave Doppler in apical four-chamber view (7). LV isovolumic relaxation time (IVRT), i.e. the time from the end of transaortic flow to the onset of early diastolic flow, was assessed by placing the continuous-wave cursor Doppler beam across the LV outflow tract in the proximity of the mitral valve anterior leaflet (7). The intraobserver variability of measures of diastolic filling parameters, calculated as the percentage difference between reading sessions (6) was $<8 \%$.

\section{Derived variables}

Heart rate (HR) was calculated as the 60/the time, in seconds, between two consecutive QRS complexes from ECG on echo-tracings. Pulse pressure (PP) was systolic - diastolic BP, and mean BP was diastolic $\mathrm{BP}+\mathrm{PP} / 3$. LV mass was calculated by the following anatomically validated Penn-cube formula (8):

$$
1.04 \times\left[(\mathrm{EDD}+\mathrm{EDIVS}+\mathrm{EDPWT})^{3}-(\mathrm{EDD})^{3}\right]-13.6
$$

and was indexed for body surface area. LV stroke volume was EDV-ESV, and was indexed by body surface area to calculate stroke index (SI). Cardiac index (CI) was calculated as SI $\times$ HR. Systemic vascular resistance (SVR) was calculated as (mean $\mathrm{BP} /$ cardiac output) $\times 80$. LV myocardial contractility was estimated based on the afterload-shortening relationship $(9,10)$. Because most of the LV myocardial fibers are orientated circumferentially and located at midwall, LV afterload and fractional shortening were calculated at this site. Specifically, afterload was estimated by LV midwall circumferential end-systolic stress (CESS) using the following validated formula (11):

$$
\frac{\text { Systolic BP } \times(\mathrm{ESD} / 2)^{2} \times\left\{1+\frac{[(\mathrm{ESD} / 2)+\mathrm{ESPWT}]^{2}}{\left[(\mathrm{ESD} / 2)+(\mathrm{ESPWT} / 2]^{2}\right.}\right\}}{[(\mathrm{ESD} / 2)+\mathrm{ESPWT}]^{2}-(\mathrm{ESD} / 2)^{2}}
$$

and LV midwall fractional shortening (MWS) was calculated using the following validated formula (10):

$$
100 \times \frac{(\mathrm{EDD}+\mathrm{EDIVS} / 2+\mathrm{EDPWT} / 2)-(\mathrm{ESD}+\mathrm{Hs})}{(\mathrm{EDD}+\mathrm{EDIVS} / 2+\mathrm{EDPWT} / 2)}
$$

where Hs is the LV inner shell in systole calculated as follows:

$$
\begin{aligned}
& {\left[(\mathrm{EDD}+\mathrm{EDIVS} / 2+\mathrm{EDPWT} / 2)^{3}-(\mathrm{EDD})^{3}\right.} \\
& \left.+(\mathrm{ESD})^{3}\right]^{0.333}-\mathrm{ESD}
\end{aligned}
$$

The computation of the inner shell in systole is based on the assumption that the total LV mass does not change during the cardiac cycle (10). Thus, individual 
LV MWS was compared with LV MWS predicted for measured CESS using the following equation developed in a reference population (10):

$$
\text { predicted MWS }=(-0.022 \times \text { CESS })+20.01
$$

and the percentage ratio of observed and predicted MWS, termed 'stress-corrected MWS', was used as an index of myocardial contractility (10). This approach allows assessment of myocardial contractility because myocardial shortening and stress are on the same axis. Total arterial stiffness was estimated as $\mathrm{PP} /$ stroke volume (12).

\section{Statistical analysis}

The statistical analysis was performed using SPSS v. 9.0.1 for Windows (SPSS, Chicago, IL, USA). Data in the text and tables are expressed as mean values and S.D. The two-tailed unpaired Student's t-test was used to compare continuous variables in hyperthyroid patients and control subjects. The two-tailed paired Student's t-test was used to analyze the effects of bisoprolol in the subgroup of treated hyperthyroid patients. A $P$ value less than 0.05 was considered statistically significant.

\section{Results}

\section{Hyperthyroid patients vs healthy euthyroid controls (Table 1)}

Compared with controls, hyperthyroid patients had a higher $\mathrm{HR}(+37 \%)$, systolic $\mathrm{BP}(+8 \%)$ and $\mathrm{PP}$
$(+53 \%)$, a lower diastolic BP $(-17 \%)$, and similar mean BP. The LV mass index was similar in hyperthyroid patients and in controls $(105 \pm 23$ vs $98 \pm 16$, $P=0.265)$. Compared with controls, hyperthyroid patients had a higher LV SI $(+22 \%)$, with a larger EDVI $(+11 \%)$, and similar ESVI. LV CESS (an index of afterload) was similar and stress-corrected LV MWS (an index of myocardial contractility) was marginally increased in hyperthyroid patients versus controls ( $+5 \% ; P=0.066)$. Compared with controls, hyperthyroid patients had a higher E wave $(+14 \%)$ and A wave $(+19 \%)$ of LV filling, but a similar E/A, and a shorter IVRT $(-30 \%)$. CI was increased $(+64 \%)$ and SVR was lower $(-43 \%)$ in hyperthyroid patients than in controls. As shown in Fig. 1, the PP/stroke volume (an index of total arterial stiffness) was about 29\% higher in hyperthyroid patients versus controls $(0.99 \pm 0.27$ vs $0.77 \pm 0.18 \mathrm{mmHg} / \mathrm{ml} ; P<0.01)$.

\section{Acute effects of bisoprolol treatment in hyperthyroid patients (Table 2)}

In 10 treated hyperthyroid patients, bisoprolol reduced HR $(-17 \%)$, systolic BP $(-11 \%)$ and pp $(-25 \%)$, and slightly increased diastolic BP $(+7 \%)$, without affecting mean BP. After bisoprolol, LV SI was slightly increased $(+6 \%)$ due to a larger EDVI (+9\%), whereas ESVI was essentially unchanged. The treatment had no significant effect on LV CESS, nor did it affect stress-corrected LV MWS. Bisoprolol increased the E/A ratio (+23\%) mostly by decreasing the A wave $(-16 \%)$, and it marginally prolonged the IVRT. After bisoprolol, CI was

Table 1 Clinical characteristics, left ventricular structure and function, and hemodynamics in overt hyperthyroid patients and in matched healthy euthyroid controls. Results are means \pm S.D.

\begin{tabular}{|c|c|c|c|}
\hline & Controls $(n=20)$ & Hyperthyroid patients $(n=20)$ & $\boldsymbol{P}$ \\
\hline Age (years) & $34 \pm 6$ & $33 \pm 8$ & 0.598 \\
\hline $\operatorname{Sex}(m / f)$ & $6 / 14$ & $6 / 14$ & - \\
\hline $\operatorname{BSA}\left(\mathrm{m}^{2}\right)$ & $1.72 \pm 0.16$ & $1.68 \pm 0.21$ & 0.494 \\
\hline $\mathrm{BMI}\left(\mathrm{kg} / \mathrm{m}^{2}\right)$ & $24 \pm 3$ & $22 \pm 4$ & 0.115 \\
\hline HR (beats/min) & $75 \pm 9$ & $103 \pm 16$ & $<0.001$ \\
\hline Systolic BP (mmHg) & $117 \pm 10$ & $126 \pm 15$ & 0.025 \\
\hline Diastolic BP (mmHg) & $74 \pm 8$ & $62 \pm 11$ & $<0.001$ \\
\hline $\mathrm{PP}(\mathrm{mmHg})$ & $42 \pm 7$ & $65 \pm 14$ & $<0.001$ \\
\hline Mean BP (mmHg) & $88 \pm 8$ & $83 \pm 11$ & 0.091 \\
\hline $\operatorname{EDVI}\left(\mathrm{ml} / \mathrm{m}^{2}\right)$ & $52 \pm 7$ & $58 \pm 9$ & 0.027 \\
\hline ESVI $\left(\mathrm{ml} / \mathrm{m}^{2}\right)$ & $19 \pm 4$ & $18 \pm 5$ & 0.302 \\
\hline $\mathrm{SI}\left(\mathrm{ml} / \mathrm{m}^{2}\right)$ & $33 \pm 6$ & $40 \pm 5$ & $<0.001$ \\
\hline MWS (\%) & $18 \pm 2$ & $20 \pm 1$ & 0.011 \\
\hline CESS (kdyne/cm²) & $111 \pm 20$ & $101 \pm 24$ & 0.153 \\
\hline Stress-corrected MWS (\%) & $104 \pm 11$ & $110 \pm 7$ & 0.066 \\
\hline E wave $(\mathrm{cm} / \mathrm{s})$ & $77 \pm 11$ & $88 \pm 14$ & 0.009 \\
\hline A wave $(\mathrm{cm} / \mathrm{s})$ & $47 \pm 7$ & $56 \pm 13$ & 0.009 \\
\hline $\mathrm{E} / \mathrm{A}$ & $1.7 \pm 0.3$ & $1.6 \pm 0.4$ & 0.850 \\
\hline IVRT (ms) & $83 \pm 10$ & $58 \pm 12$ & $<0.001$ \\
\hline $\mathrm{Cl}\left(\mathrm{l} / \mathrm{min} / \mathrm{m}^{2}\right)$ & $2.5 \pm 0.6$ & $4.1 \pm 0.5$ & $<0.001$ \\
\hline SVR (dyne $\left.\times \mathrm{s} / \mathrm{cm}^{5}\right)$ & $1736 \pm 433$ & $989 \pm 213$ & $<0.001$ \\
\hline
\end{tabular}

BSA, body surface area; BMI, body mass index; HR, heart rate; BP, blood pressure; PP, pulse pressure; EDVI, left ventricular end-diastolic volume index; ESVI, left ventricular end-systolic volume index; SI, stroke index; MSW, left ventricular midwall fractional shortening; CESS, left ventricular midwall circumferential end-systolic stress; IVRT, isovolumic relaxation time; Cl, cardiac index; SVR, systemic vascular resistance. $\mathrm{kdyne}_{\mathrm{cm}} \mathrm{cm}^{2}$ and dyne $\times \mathrm{s} / \mathrm{cm}^{5}$, standard units for CESS and SVR, respectively. 


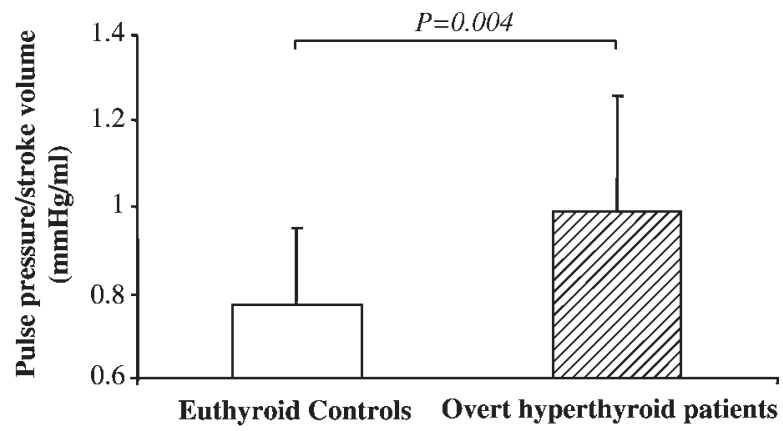

Figure 1 Pulse pressure to stroke volume ratio in overt hyperthyroid patients $(n=20)$ and in matched healthy euthyroid controls $(n=20)$.

reduced $(-12 \%)$ and SVR was increased $(+12 \%)$. As shown in Fig. 2, after bisoprolol treatment, the $\mathrm{PP} /$ stroke volume was reduced by about $30 \%$ in hyperthyroid patients $(0.99 \pm 0.22$ vs $0.70 \pm 0.19$ $\mathrm{mmHg} / \mathrm{ml} ; \mathrm{P}<0.001)$.

\section{Treated hyperthyroid patients vs healthy euthyroid controls (Table 2)}

Compared with controls, treated hyperthyroid patients had only a marginally faster HR and similar systolic, diastolic and mean BP, whereas PP remained higher $(+24 \%)$. LV SI was further increased $(+42 \%)$ in treated hyperthyroid patients versus controls, through a further enlargement in EDVI $(+26 \%)$, without changes in ESVI. Compared with controls, treated patients had a similar LV CESS and near equal stress-corrected LV MWS. After bisoprolol treatment, hyperthyroid patients had a higher E wave $(+20 \%)$ than controls, but similar A wave and E/A, whereas IVRT remained shorter $(-19 \%)$. Table 2 shows that compared with controls, treated hyperthyroid patients had a higher CI $(+58 \%)$ and a reduced SVR $(-34 \%)$. As shown in Fig. 2, $\mathrm{PP} /$ stroke volume was similar between treated patients and controls $(0.70 \pm 0.19$ vs $0.77 \pm 0.12 \mathrm{mmHg} / \mathrm{ml}$, $P=0.339$ )

\section{Discussion}

Two main findings emerge from our study on the impact of human overt hyperthyroidism on the cardiovascular system. The first is that myocardial contractility does not play a major role in increasing LV performance in overt hyperthyroid patients, which is instead predominantly sustained by increased preload, with enhanced LV diastolic function. In fact, compared with controls, our hyperthyroid patients showed only a marginal increase in stress-corrected MWS, which is an index of myocardial contractility. By contrast, in our hyperthyroid patients, the supra-normal EDVI despite the remarkably faster HR is evidence of a net increase in preload given the inverse relationship between these variables (13). Augmented preload in hyperthyroid patients is also supported by our observation of an increase in the $\mathrm{E}$ wave of $\mathrm{LV}$ diastolic filling in patients versus controls, which, given the faster $H R$ in the former, is indicative of a greater left atrium-LV pressure

Table 2 Clinical characteristics, left ventricular structure and function, and hemodynamics in a randomly selected subgroup of overt hyperthyroid patients $(\mathrm{H})$ before and 2 hours after $5 \mathrm{mg}$ bisoprolol given orally, as compared with matched healthy euthyroid controls (C). Data are means \pm S.D.

\begin{tabular}{|c|c|c|c|c|c|}
\hline & $\begin{array}{l}\text { H before bisoprolol } \\
(n=10)\end{array}$ & $\begin{array}{c}P \\
\text { H before vs after }\end{array}$ & $\begin{array}{l}\text { H after bisoprolol } \\
(n=10)\end{array}$ & $\begin{array}{l}\text { Controls } \\
(n=10)\end{array}$ & $\begin{array}{c}P \\
C \text { vs } \stackrel{H}{H} \text { after }\end{array}$ \\
\hline Age (years) & $30 \pm 5$ & - & - & $30 \pm 3$ & - \\
\hline $\operatorname{Sex}(m / f)$ & $5 / 5$ & - & - & $5 / 5$ & - \\
\hline $\operatorname{BSA}\left(\mathrm{m}^{2}\right)$ & $1.70 \pm 0.15$ & - & - & $1.80 \pm 0.17$ & - \\
\hline $\mathrm{BMI}\left(\mathrm{kg} / \mathrm{m}^{2}\right)$ & $22 \pm 2$ & - & - & $24 \pm 3$ & - \\
\hline HR (beats/min) & $103 \pm 11$ & $<0.001$ & $86 \pm 9$ & $78 \pm 8$ & 0.061 \\
\hline Systolic BP (mmHg) & $128 \pm 5$ & $<0.001$ & $114 \pm 6$ & $112 \pm 9$ & 0.423 \\
\hline Diastolic BP (mmHg) & $59 \pm 9$ & 0.108 & $63 \pm 12$ & $70 \pm 9$ & 0.152 \\
\hline $\mathrm{PP}(\mathrm{mmHg})$ & $69 \pm 8$ & $<0.001$ & $52 \pm 9$ & $42 \pm 5$ & 0.005 \\
\hline Mean BP (mmHg) & $82 \pm 7$ & 0.368 & $80 \pm 10$ & $84 \pm 9$ & 0.353 \\
\hline EDVI $\left(\mathrm{ml} / \mathrm{m}^{2}\right)$ & $58 \pm 9$ & 0.001 & $64 \pm 9$ & $49 \pm 6$ & $<0.001$ \\
\hline ESVI $\left(\mathrm{ml} / \mathrm{m}^{2}\right)$ & $16 \pm 5$ & 0.148 & $19 \pm 6$ & $19 \pm 3$ & 0.999 \\
\hline $\mathrm{SI}\left(\mathrm{ml} / \mathrm{m}^{2}\right)$ & $42 \pm 5$ & 0.017 & $45 \pm 6$ & $30 \pm 4$ & $<0.001$ \\
\hline MWS (\%) & $19 \pm 1$ & 0.310 & $19 \pm 1$ & $18 \pm 1$ & 0.229 \\
\hline CESS (kdyne/cm²) & $107 \pm 14$ & 0.486 & $110 \pm 11$ & $114 \pm 24$ & 0.659 \\
\hline Stress-corrected MWS (\%) & $109 \pm 7$ & 0.356 & $106 \pm 8$ & $103 \pm 9$ & 0.350 \\
\hline $\mathrm{E}(\mathrm{cm} / \mathrm{s})$ & $92 \pm 10$ & 0.674 & $93 \pm 6$ & $77 \pm 13$ & 0.003 \\
\hline $\mathrm{A}(\mathrm{cm} / \mathrm{s})$ & $61 \pm 16$ & 0.009 & $50 \pm 7$ & $46 \pm 6$ & 0.157 \\
\hline$E / A$ & $1.5 \pm 0.2$ & 0.002 & $1.9 \pm 0.2$ & $1.7 \pm 0.3$ & 0.187 \\
\hline IVRT (ms) & $60 \pm 8$ & 0.168 & $63 \pm 10$ & $76 \pm 7$ & 0.004 \\
\hline $\mathrm{Cl}\left(\mathrm{l} / \mathrm{min} / \mathrm{m}^{2}\right)$ & $4.4 \pm 0.8$ & $<0.001$ & $3.9 \pm 0.8$ & $2.4 \pm 0.4$ & $<0.001$ \\
\hline SVR $\left(\right.$ dyne $\left.\times \mathrm{s} / \mathrm{cm}^{5}\right)$ & $904 \pm 182$ & 0.027 & $1019 \pm 277$ & $1608 \pm 194$ & $<0.001$ \\
\hline
\end{tabular}

See Table 1 for abbreviations. 


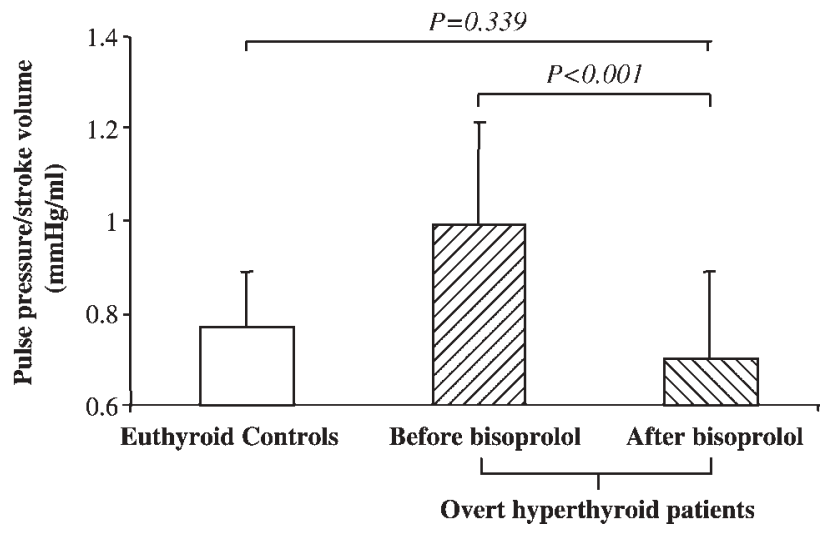

Figure 2 Pulse pressure to stroke volume ratio in a subgroup of randomly selected overt hyperthyroid patients $(n=10)$ before and $2 \mathrm{~h}$ after $5 \mathrm{mg}$ bisoprolol given orally, as compared with matched healthy euthyroid controls $(n=10)$.

gradient due to augmented venous return. In fact, in the absence of a simultaneous increase in preload, the faster HR would be associated with a decrease in the $\mathrm{E}$ wave (14). In addition, in line with previous reports (15-18), hyperthyroid patients also had a shorter IVRT suggesting optimal diastolic function. This probably helped to accommodate the increased preload without relevant changes in LV filling pressure potentially through enhancement of LV suction (19).

Using echocardiography, Feldman et al. (20) found that LV circumferential fiber shortening velocity at the endocardial level, corrected for HR and LV meridional end-systolic stress, was higher in 11 hyperthyroid patients than in age-matched controls. They concluded that increased myocardial contractility plays a mandatory role in increasing LV systolic performance. However, it should be emphasized that the estimation of myocardial contractility by endocardial fiber shortening velocity may overestimate the true myocardial inotropic state, especially when preload and HR are increased (21). By contrast, assessment of myocardial contractility by relating MWS to CESS provides a more physiological measure of the myocardial inotropic state (10). In fact, most of the LV myocardial fibers are oriented circumferentially and are located at midwall, which is where shortening and stress are de facto measured $(10,11)$. Indeed, our findings that myocardial contractility does not play a major role in increasing LV performance in human overt hyperthyroidism is in agreement with a report by Merillon et al. (22), who assessed LV systolic function by cardiac catheterization in 7 thyrotoxic patients and 11 normal controls atrially paced at a near identical heart rate, and found no differences between the two groups in several parameters of LV contractile performance. They concluded that in human hyperthyroidism there is no increase in the level of myocardial contractility independent of changes in heart rate.

The second major finding of our study is that total arterial stiffness is increased in overt hyperthyroid patients. In fact, compared with controls, our hyperthyroid patients had a higher $\mathrm{PP} /$ stroke volume because of disproportionately increased PP with respect to stroke volume. It is noteworthy that the higher $\mathrm{PP} /$ stroke volume in our hyperthyroid patients was associated with a fairly normal mean $\mathrm{BP}$, indicating that the increase in total arterial stiffness was not due to a higher arterial load at the onset of LV ejection. Accordingly, one mechanism that would explain our finding is that the faster $\mathrm{HR}$ in overt hyperthyroidism results in an earlier return of the forward pressure wave in systole, thereby resulting in a greater overlapping in the forward and reflected pressure waves. The clinical outcome of this physiological process would be an increase in systolic BP and a decrease in diastolic BP, with a net increase in PP and an essentially unchanged mean BP (23). This hypothesis is supported by the fact that, in bisoprololtreated patients, the decrease in HR was accompanied by a reduction in systolic BP and by a slight elevation in diastolic BP, with a net decrease in PP and quite unchanged mean BP, whereas stroke volume was further increased, thereby resulting in normalization of the $\mathrm{PP} /$ stroke volume. Because the hemodynamic setting of overt hyperthyroid patients is strikingly like that of athletes performing physical exercise (24), it is a tempting to speculate that, in overt human hyperthyroidism, the increase in total arterial stiffness represents an important dynamic adaptation to allow a faster transfer of blood from the LV towards the peripheral vascular tree, which, in turn, sustains the hyperkinetic circulatory state.

In conclusion, in human overt hyperthyroidism, myocardial contractility does not play a major role in increasing LV performance, which is instead predominantly sustained by increased preload with enhanced $\mathrm{LV}$ diastolic function. In addition, human thyrotoxicosis is associated with increased total arterial stiffness despite a fairly normal mean BP. In this scenario, acute $\beta_{1}$-adrenergic blockade blunts the thyrotoxic cardiovascular hyperkinesia predominantly by slowing HR - a process that is associated with normalization of total arterial stiffness.

\section{Acknowledgements}

We are grateful to Jean Ann Gilder for editing the text.

\section{References}

1 Klein I \& Ojamaa K. Thyroid hormone and the cardiovascular system. New England Journal of Medicine 2001344 501-509.

2 Biondi B, Palmieri EA, Lombardi G \& Fazio S. Effects of thyroid hormone on cardiac function: the relative importance of heart rate, loading conditions, and myocardial contractility in the regulation of cardiac performance in human hyperthyroidism. Journal of Clinical Endocrinology and Metabolism 2002 87 968-974.

3 Sahn DJ, DeMaria A, Kisslo J \& Weyman A. The Committee on M-mode Standardization of the American Society of Echocardiography: recommendations regarding quantitation in M-mode 
echocardiography: results of a survey of echocardiographic measurements. Circulation $1978 \mathbf{5 8} 1072-1083$.

4 Devereux RB \& Reichek N. Echocardiographic determination of left ventricular mass in man. Anatomic validation of the method. Circulation 197755 613-618.

5 Wahr DW, Wang YS \& Schiller NB. Left ventricular volumes determined by two-dimensional echocardiography in a normal adult population. Journal of American College of Cardiology 19831 $863-868$.

6 Cittadini A, Fazio S, D’Ascia C. Basso A. Bazzicalupo L, Picardi G \& Sacca L. Subclinical cardiotoxicity by doxorubicin: a pulse Doppler echocardiographic study. European Heart Journal 199112 1000-1005.

7 Fazio S, Cittadini A, Sabatini D, Merola B, Colao AM, Biondi B, Lombardi G \& Sacca L. Evidence for biventricular involvement in acromegaly: a Doppler echocardiographic study. European Heart Journal $1993 \mathbf{1 4} 26-33$.

8 Devereux RB, Alonso DR, Lutas EM, Gottlieb GJ, Campo E, Sachs I \& Reichek N. Echocardiographic assessment of left ventricular hypertrophy: comparison to necropsy findings. American Journal of Cardiology $1986 \mathbf{5 7}$ 450-458.

9 Gaasch WH, Zile MR, Hoshino PK, Apstein CS \& Blaustein AS. Stress-shortening relations and myocardial blood flow in compensated and failing canine hearts with pressure-overload hypertrophy. Circulation $1989 \mathbf{7 9} 872-883$.

10 de Simone G, Devereux RB, Roman MJ. Ganau A, Saba PS, Alderman MH \& Laragh JH. Assessment of left ventricular function by the midwall fractional shortening/end-systolic stress relation in human hypertension. Journal of American College of Cardiology 199423 1444-1451.

11 Shimizu G, Hirota Y, Kita Y, Kawamura K, Saito T \& Gaasch WH. Left ventricular midwall mechanics in systemic arterial hypertension. Myocardial function is depressed in pressure-overload hypertrophy. Circulation 199183 1676-1684.

12 de Simone G, Roman MJ. Daniels SR, Mureddu G, Kimball TR, Greco R \& Devereux RB. Age-related changes in total arterial capacitance from birth to maturity in a normotensive population. Hypertension 199729 1213-1217.

13 Erbel R, Schweizer P, Krebs W, Langen HJ, Meyer J \& Effert S. Effects of heart rate changes on left ventricular volume and ejection fraction: a 2-dimensional echocardiographic study. American Journal of Cardiology 198453 590-597.

14 Oh JK, Appleton CP, Hatle LK, Nishimura RA, Seward JB \& Tajik AJ. The noninvasive assessment of left ventricular diastolic function with two-dimensional and Doppler echocardiography. Journal of American Society of Echocardiography $1997 \mathbf{1 0}$ $246-270$.

15 Lewis BS, Ehrenfeld EN, Lewis N \& Gotsman MS. LV function in thyrotoxicosis. American Heart Journal 197997 460-468.

16 Friedman MJ, Okada RD, Ewy GA \& Hellman DJ. Left ventricular systolic and diastolic function in hyperthyroidism. American Heart Journal $19821041303-1308$.

17 Mintz G, Pizzarello R \& Klein I. Enhanced left ventricular diastolic function in hyperthyroidism: noninvasive assessment and response to treatment. Journal of Clinical Endocrinology and Metabolism 199173 146-150.

18 Kahaly GJ, Wagner S, Nieswandt J, Mohr-Kahaly S \& Ryan TJ. Stress echocardiography in hyperthyroidism. Journal of Clinical Endocrinology and Metabolism 199984 2308-2313.

19 Udelson JE, Bacharach SL, Cannon RO 3rd \& Bonow RO. Minimum left ventricular pressure during beta-adrenergic stimulation in human subjects. Evidence for elastic recoil and diastolic "suction' in the normal heart. Circulation 199082 1174-1182.

20 Feldman T, Borow KM, Sarne DH, Neumann A \& Lang RM. Myocardial mechanics in hyperthyroidism: importance of left ventricular loading conditions, heart rate and contractile state. Journal of American College of Cardiology 19867 967-974.

21 Roman MJ. Devereux RB \& Cody RJ. Ability of left ventricular stress-shortening relations, end-systolic stress/volume ratio and indirect indexes to detect severe contractile failure in ischemic or idiopathic dilated cardiomyopathy. American Journal of Cardiology $1989641338-1343$.

22 Merillon JP. Passa P. Chastre J. Wolf A \& Gourgon R. Left ventricular function and hyperthyroidism. British Heart Journal 198146 $137-143$.

23 Pythoud F, Stergiopulos N \& Meister JJ. Separation of arterial pressure waves into their forward and backward running components. Journal of Biomechanical Engineering 1996118 295-301.

24 Di Bello V, Talarico L, Di Muro C, Santoro G, Bertini A, Giorgi D, Caputo MT, Bianchi M, Cecchini L \& Giusti C. Evaluation of maximal left ventricular performance in elite bicyclists. International Journal of Sports Medicine 199516 498-506.

Received 21 August 2003

Accepted 1 March 2004 